\title{
Estética analítica: entre el pragmatismo y el neopragmatismo*
}

\author{
Analytical aesthetic: \\ Between pragmatism and neo-pragmatism \\ Estética analítica: \\ Entre o pragmatismo e o neo-pragmatismo
}

Fecha de entrega: 24 de agosto de 2013

Fecha de aprobación: 20 de diciembre de 2013

Yebrail Castañeda Lozano ${ }^{* *}$

Los doctores Porfirio Cardona-Restrepo y Freddy Santamaría Velasco iniciaron la edición de esta obra titulada Estética analítica: entre el pragmatismo y el neopragmatismo, en el primer semestre del año de 2013, en el ambiente académico del Doctorado de Filosofía de la Universidad Santo Tomás. Los autores emprendieron la tarea de publicar unos artículos reflexivos sobre el asunto estético desde la perspectiva de las vertientes filosóficas de la analítica, la pragmática y la neopragmática con el sello editorial de la Universidad Pontificia Bolivariana.

El propósito de este texto, como se afirma en la presentación, es realizar un diálogo de forma plural con las distintas escuelas y formas de pensamiento sobre el tema de la estética. El texto comprende de cuatro partes: una introducción por parte de los editores titulada "De la analítica a la estética neopragmática". La segunda parte trata

\footnotetext{
* Cardona-Restrepo, P., y Santamaría Velasco, F. (Eds.). (2014). Estética analítica: Entre el pragmatismo y el neopragmatismo. Medellin: Universidad Pontificia Bolivariana. 342p. ISBN: 978-958-764-158-5

** Profesor de la Universidad de la Salle. Correo electrónico: ycastaneda@unisalle.edu.co
} 
sobre las temáticas del pragmatismo clásico. La tercera parte aborda precisamente la estética analítica en Wittgenstein. Finaliza la obra con la reflexión sobre la estética y el neopragmatismo.

Los títulos centrales de cada uno de estos grandes apartados se constituyen de la siguiente forma:

La introducción "De la analítica a la estética neopragmática” comprende los artículos de Porfirio Cardona "Richard Shuterman y la estética neopragmática" y de Freddy Santamaría "Esplendor, miseria y resplandor de la filosofía analítica: De la analítica al neopragmatismo". En estas dos presentaciones, los autores coinciden con que la filosofía y la estética no son procesos especulativos sino actividades humanas autocurativas cuyo éxito o fracaso se debe precisamente a quién se atreve a realizar la labor de pensar.

La segunda parte trata sobre el pragmatismo clásico. En esta, se encuentran los artículos de César Pongutá "La estética de Peirce en sus consideraciones sobre el pragmatismo"; de Nubiola y Barrena "Charles S. Peirce: creatividad y significación: hacia una estética pragmatista"; de Vladimir Sánchez "El pragmaticismo peirciano y su proyección en las estéticas comunicativas contemporáneas: el caso de la construcción del sentido publicitario"; de Martha Patiño "La experiencia estética o la plena experiencia: el desplazamiento del espectador al artista en John Dewey", y de Diego Pineda "La relación entre arte y democracia desde la perspectiva de John Dewey".

En estas presentaciones, hechas desde la perspectiva del pragmatismo clásico, la estética tiene su propia normatividad cuya realidad es proyectada por la acción y el pensamiento. La belleza es sinónimo de verdad, que se goza mediante la contemplación y se comunica con el arte. Su análisis se interpreta en el signo como una identidad total. La estética ya no se encuentra en los objetos bellos sino en las actividades ordinarias, su universalización de esta experiencia no solo se queda en la cotidianidad sino que es una expresión propia de la democracia.

La tercera parte es sobre estética analítica. Se presentan los artículos de Alejandro Tomasini "Wittgenstein: obra de arte y estética” y de Yebrail Castañeda L. "La estética y belleza subrepticia y ostensible en las proposiciones tautológicas y contradictorias". La estética y la analítica en Wittgenstein se ocupan de las aclaraciones conceptuales a través de análisis gramaticales, de formas de vida y de los juegos de lenguaje. La 
estética del esclarecimiento se encuentra subyacente u oscilante en una tautología o en una contradicción conforme a su condición de verdadera o falsa.

La cuarta y última parte es "La estética y el neopragmatismo". Se tienen los artículos de Carlos Jiménez con el título "La estética como praxis y la estética como discurso: aporte brandomianos"; de Alberto Ramírez con "La creación divina como acto lingüístico performativo y su connotación estética desde una mirada pragmática", y de Mauricio Beuchot con "Hacia una estética analógica, desde el pragmatismo". La metafísica tradicional entendía la estética como la sensibilidad hacia la belleza. En el neopragmatismo, la estética es un entrenamiento que se encuentra sus bases en las prácticas sociales. Esta estética salva el naturalismo erigiéndose como una alternativa válida para reconocer en la experiencia de la práctica en la creación divina. La estética en la historia se ha alterado en las nociones de arte como belleza, composición, impacto y proporción.

Esta obra cumple su propósito de posibilitar un diálogo abierto y diverso con las distintas corrientes y espíritus del pensamiento filosófico contemporáneo: desde la perspectiva de la estética analítica hasta el marco del pragmatismo y del neopragmatismo. Este texto invita y logra tender puentes para reflexionar los problemas estéticos de la contemplación, la sensibilidad, el lenguaje, la normatividad y la performatividad. 